\title{
Água subterrânea para abastecimento público na Região Metropolitana de São Paulo: é possivel utilizá-la em larga escala?
}

\section{Groundwater for public supply in the Metropolitan Region of São Paulo: is it possible to use it on a large scale?}

Reginaldo Bertolo $^{(1)}$; Ricardo Hirata ${ }^{(1)}$; Bruno Conicelli ${ }^{(1)}$; Mateus Simonato ${ }^{(1)}$; Antonio Pinhatti ${ }^{(1)}$; Amélia Fernandes ${ }^{(1,2)}$.

DOI: $10.4322 /$ dae.2014.148

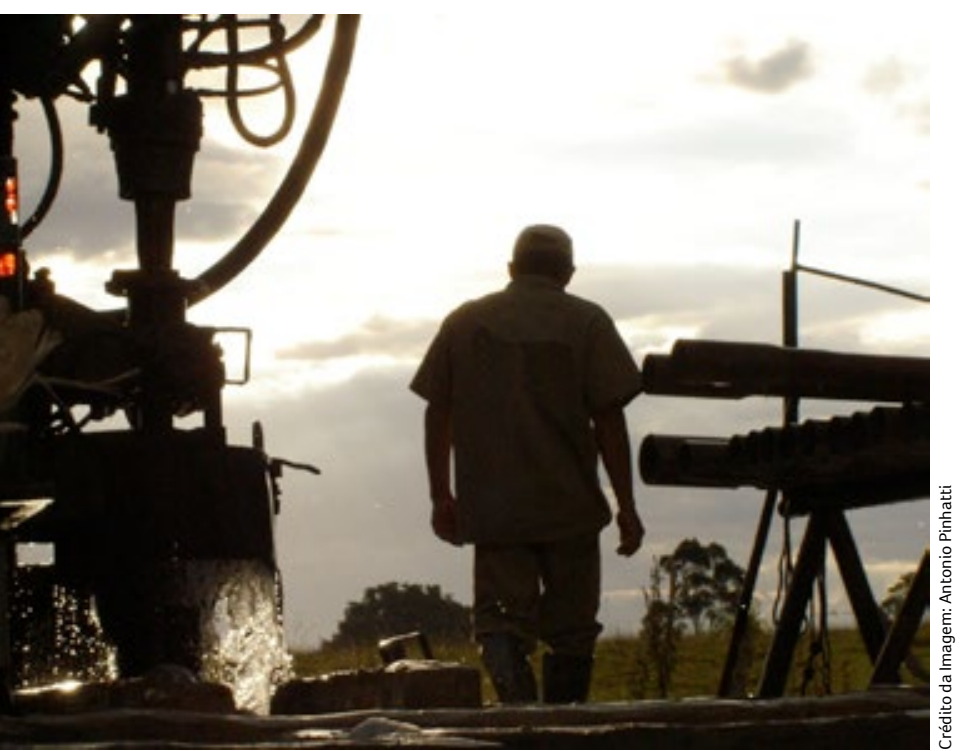

Os principais reservatórios de água de abastecimento da Região Metropolitana de São Paulo (RMSP) encontram-se, nos dias atuais (março de 2015), com estoques próximos dos limites baixos, porém em processo de leve recuperação por conta das chuvas de verão. Nestes tempos, a imprensa tem publicado diariamente a situação da crise hídrica e a sociedade mantém-se atônita com as notícias das variações diárias dos estoques de água e atenta às discussões sobre o racionamento que pode ou não ocorrer em algum momento ao longo de 2015.

O indesejado racionamento no abastecimento poderá ser possivelmente evitado caso ocorra a conjugação de alguns fatores: chuvas com volumes acima da média nos próximos meses; conclusão de obras emergenciais até meados de 2015 que visam a remanejar e aumentar a oferta de água dentro da própria Bacia do Alto Tietê; esforço concentrado para a diminuição de perdas de água tratada; aumento do reúso; e mobilização da sociedade para a redução do consumo per capita.

No que se refere ao manejo de oferta de água, as obras emergenciais visam especialmente a aliviar o peso da importância do Sistema Cantareira no abastecimento, trazendo água de outros reservatórios da RMSP menos estressados. Entre as obras, encontram-se as que objetivam levar água da Represa Billings e de rios menores ao Sistema Guarapiranga e as que levarão água do Sistema Rio Grande (um braço da Represa Billings) e de outros rios menores ao Sistema Alto Tietê.

(1) Centro de Pesquisas de Águas Subterrâneas (CEPAS), Instituto de Geociências da Universidade de São Paulo (USP).

(2) Instituto Geológico do Estado de São Paulo (SMA, SP). 
Sabe-se, entretanto, que esse conjunto de obras não fornecerá uma quantidade de água suficiente para garantir a segurança hídrica na RMSP em longo prazo, sendo necessárias novas fontes de água no futuro. Uma reflexão sobre a importância da água subterrânea para o abastecimento público na RMSP se faz necessária nessa circunstância, tanto porque os poços tubulares profundos podem ser construídos de forma ágil e rápida para ajudar no aumento da oferta de água na situação de contingenciamento quanto porque eles podem ser utilizados em longo prazo para complementar o abastecimento público mesmo em situações de normalidade de chuvas.

Os reservatórios subterrâneos já são utilizados para abastecimento público na maior parte dos municípios do interior do estado operados pela Companhia de Saneamento Básico do Estado de São Paulo (Sabesp), com vantagens operacionais e econômicas em relação ao uso da água de reservatórios superficiais em muitos casos. É de se lamentar o fato de o tão frequentemente comentado e virtuoso Aquífero Guarani não estar um pouco mais próximo dos pés dos cidadãos paulistanos, mas é para se perguntar por quais razões os aquíferos da RMSP não são utilizados para abastecimento público. Seria porque existe a percepção de que os poços fornecem vazões muito baixas, o que faria ser necessária a operação de uma quantidade infindável e inviável de poços? Seria porque os poços privados existentes estariam numa quantidade tal que já teriam comprometido a oferta de água dos aquíferos? Seria porque há uma percepção de que a água subterrânea apresenta problemas de
É de se lamentar o fato de o tão frequentemente comentado e virtuoso Aquífero Guarani não estar um pouco mais próximo dos pés dos cidadãos paulistanos, mas é para se perguntar por quais razões os aquíferos da RMSP não são utilizados para abastecimento público. conhecidos e com oferta de água confortável até recentemente?

Procura-se, neste artigo, oferecer respostas ou mesmo elaborar reflexões sobre essas questões. $O$ texto apresenta, inicialmente, as características de reservação e circulação de água dos aquíferos da RMSP e, em seguida, uma discussão dos principais problemas relacionados com as vazões dos poços, com a operação e gestão de poços para o abastecimento público e com a qualidade da água subterrânea. $O$ texto também apresenta uma discussão da forma como se pode obter água subterrânea de qualidade e em quantidade suficiente para complementar o abastecimento público na RMSP e uma argumentação de como se pode executar uma operação adequada e racional dos poços, num contexto de gestão integrada dos recursos hídricos superficiais e subterrâneos.

\section{CARACTERIISTICAS DOS AQUIIFEROS NA RMSP}

Os aquíferos e os reservatórios de água superficial funcionam de forma similar em relação a apresentarem uma determinada geometria, bem como fluxos de entrada e de saída de água, que dependem da recarga propiciada por chuvas. As dimensões e as características de fluxo de água do reservatório subterrâneo são definidas pelo tipo e continuidade das rochas em subsuperfície, assim como pelas suas propriedades de porosidade e permeabilidade.

Há dois tipos principais de aquífero na RMSP (Figura 1): o aquífero sedimentar, localizado em áreas em que o relevo é mais suave (azul-escuro e marrom no mapa), e o aquífero cristalino tural quanto por poluição de origem humana? Ou seria também porque a comunidade técnica estaria mais acostumada a manejar os reservatórios de águas superficiais, mais fáceis de ser (em tons de verde no mapa), que, além de aflorar em locais na RMSP onde o relevo é mais acidentado, também ocorre abaixo do aquífero sedimentar. As áreas do aquífero sedimentar, grosso 


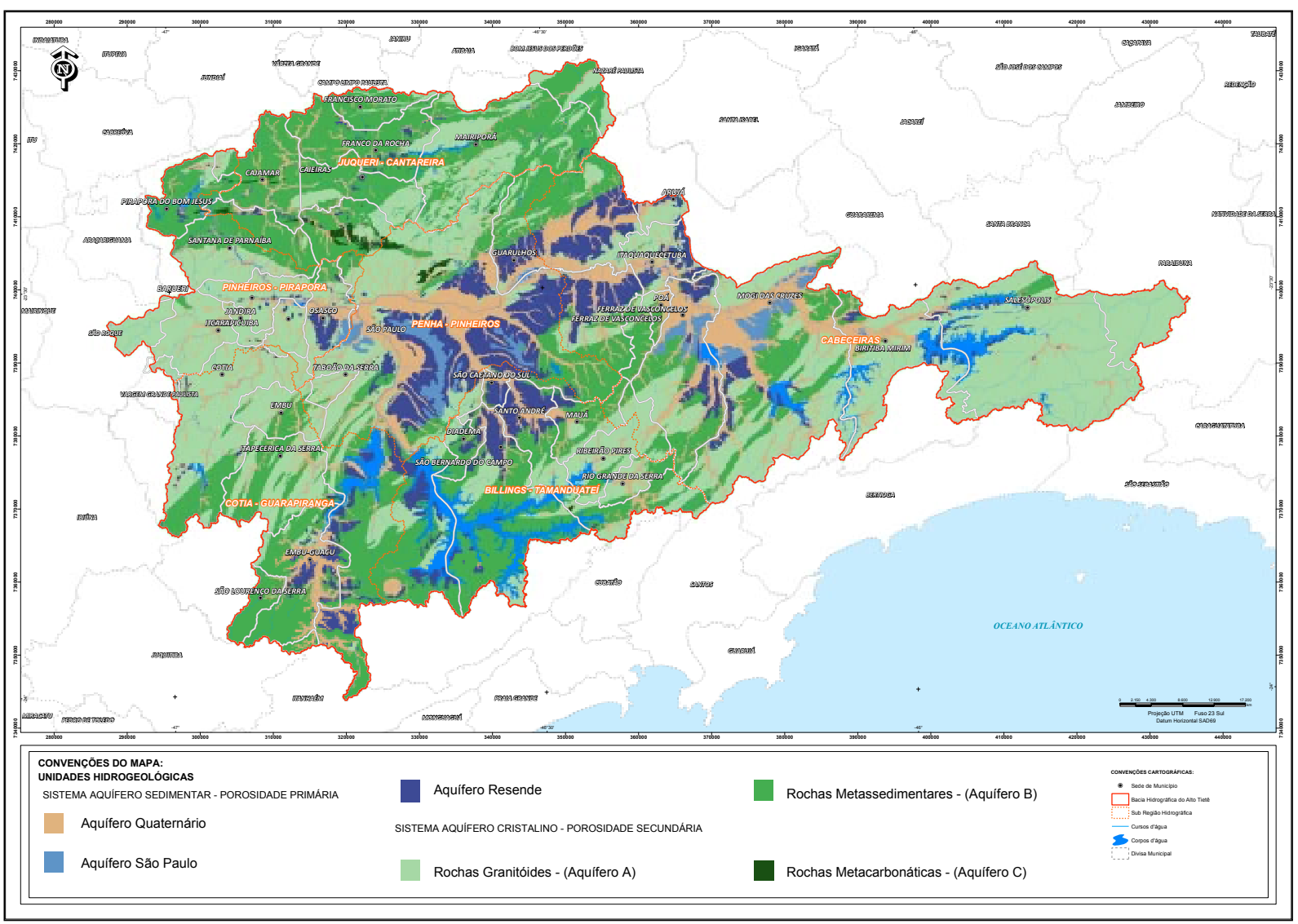

Figura 1 - Aquíferos da Bacia do Alto Tietê. Fonte: Adaptado de Hirata et al. (2012).
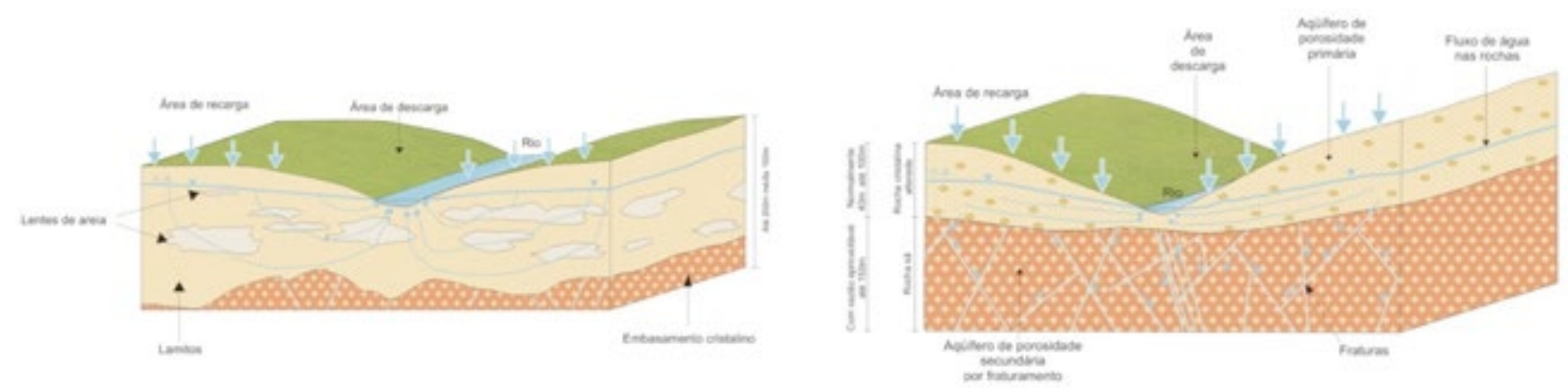

Figura 2 - Modelos conceituais dos aquíferos da Bacia do Alto Tietê.

Fonte: Adaptado de Hirata e Ferreira (2001).

modo, coincidem com as áreas de maior densidade populacional da RMSP. Os modelos conceituais desses aquíferos (Figura 2 ) indicam que o aquífero sedimentar apresenta espessura média de 100 $\mathrm{m}$ e a água circula pelos poros intergranulares do material geológico, formado essencialmente por lentes de areia em meio a lamitos. Já no aquífero cristalino, a água encontra-se nas fraturas das rochas graníticas e gnáissicas e também nos poros do manto de intemperismo dessas rochas numa seção de espessura total de até aproximadamente $250 \mathrm{~m}$ de aquífero com vazões aproveitáveis (HIRATA; FERREIRA, 2001; HIRATA et al., 2002). Para ambos os aquíferos, as chuvas que se infil- 
tram no subsolo participam de sua recarga e os rios e drenagens da bacia funcionam como área de descarga por meio dos fluxos de base. É essa água subterrânea do fluxo de base que fornece o serviço ambiental de sustentação da vida aquática, de diluição dos esgotos e de recarga dos reservatórios superficiais de abastecimento público em épocas de estiagem.

A recarga dos aquíferos se dá de forma heterogênea, em função dos diferentes usos do solo na RMSP. Nas áreas de baixa ocupação urbana, mais permeáveis, predomina a recarga natural por chuvas; nas áreas mais impermeabilizadas e de forte urbanização, as fugas das redes públicas de distribuição, coletora de esgotos e galerias pluviais podem representar mais de $50 \%$ da recarga dos aquíferos (DIAS et al., 2005).

O volume de água subterrânea disponível para consumo na RMSP é considerado, por muitos especialistas, como, por exemplo, Campos e Albuquerque Filho (2005), uma parcela de $50 \%$ do volume de recarga dos aquíferos, a fim de que os outros $50 \%$ garantam o fluxo de base dos rios. Cálculos recentes levaram em consideração o tipo de solo e a declividade da bacia; esses fatores foram inseridos no cálculo de balanço hídrico e, com isso, o volume de água que se infiltra anualmente como recarga nos aquíferos da Bacia do Alto Tietê é estimado em $53 \mathrm{~m}^{3} / \mathrm{s}$ (CONICELLI, 2014). O autor calculou também as reservas explotáveis em 33 $\mathrm{m}^{3} / \mathrm{s}$, disponíveis para ser captadas de forma se-

\section{O autor calculou também as reservas explotáveis em $33 \mathrm{~m}^{3} / \mathrm{s}$, disponiveis para ser captadas de forma segura por meio de poços profundos, sem interferir no fluxo de base dos rios.}

gura por meio de poços profundos, sem interferir no fluxo de base dos rios.

Esse número indica que o potencial de exploração dos aquíferos da RMSP é bastante significativo quando comparado com o total da atual capacidade instalada do sistema produtor metropolitano, calculado em $67,7 \mathrm{~m}^{3} / \mathrm{s}$ (FUSP, 2009). Uma parcela das reservas explotáveis dos aquíferos já vem sendo utilizada há muito tempo por usuários privados, em especial nas áreas mais fortemente urbanizadas da RMSP, como se verá adiante. Entretanto, não se pode deixar de considerar que essa vazão explotável dos aquíferos é muito expressiva e poderia ser utilizada para o abastecimento público, tanto para aliviar os problemas atuais de estresse hídrico quanto para utilização em longo prazo.

\section{AFIRMAÇÕES CORRETAS E EQUIVOCADAS SOBRE POÇOS NA RMSP}

São discutidas a seguir quatro afirmações percebidas como reais pela comunidade técnica e que talvez possam explicar a quase inexistente utilização da água de aquíferos para o abastecimento público na RMSP.

- Afirmação 1 - Os milhares de poços existentes já explotam grandes volumes, sobrando pouco para a explotação mediante novos poços para abastecimento público.

Esta afirmação está apropriada no que se refere aos volumes já explotados em várias áreas da RMSP, mas inadequada no que se refere aos volumes que ainda podem ser explotados em outras áreas. Há, de fato, milhares de poços profundos na RMSP e ninguém sabe precisar exatamente esse número e a localização exata de todos eles. Isso porque o conjunto de poços profundos irregulares, ou seja, sem registro de outorga no Departamento de Águas e Energia Elétrica (DAEE), é a grande maioria em relação à totalidade dos poços existentes em operação. Ademais, mesmo com relação aos poços outorgados, o poder público mantém um registro dos poços com informações muitas vezes incompletas, sendo impossível saber se eles de fato se encontram ativos e quais seriam os seus reais regimes de operação. Essa situação 


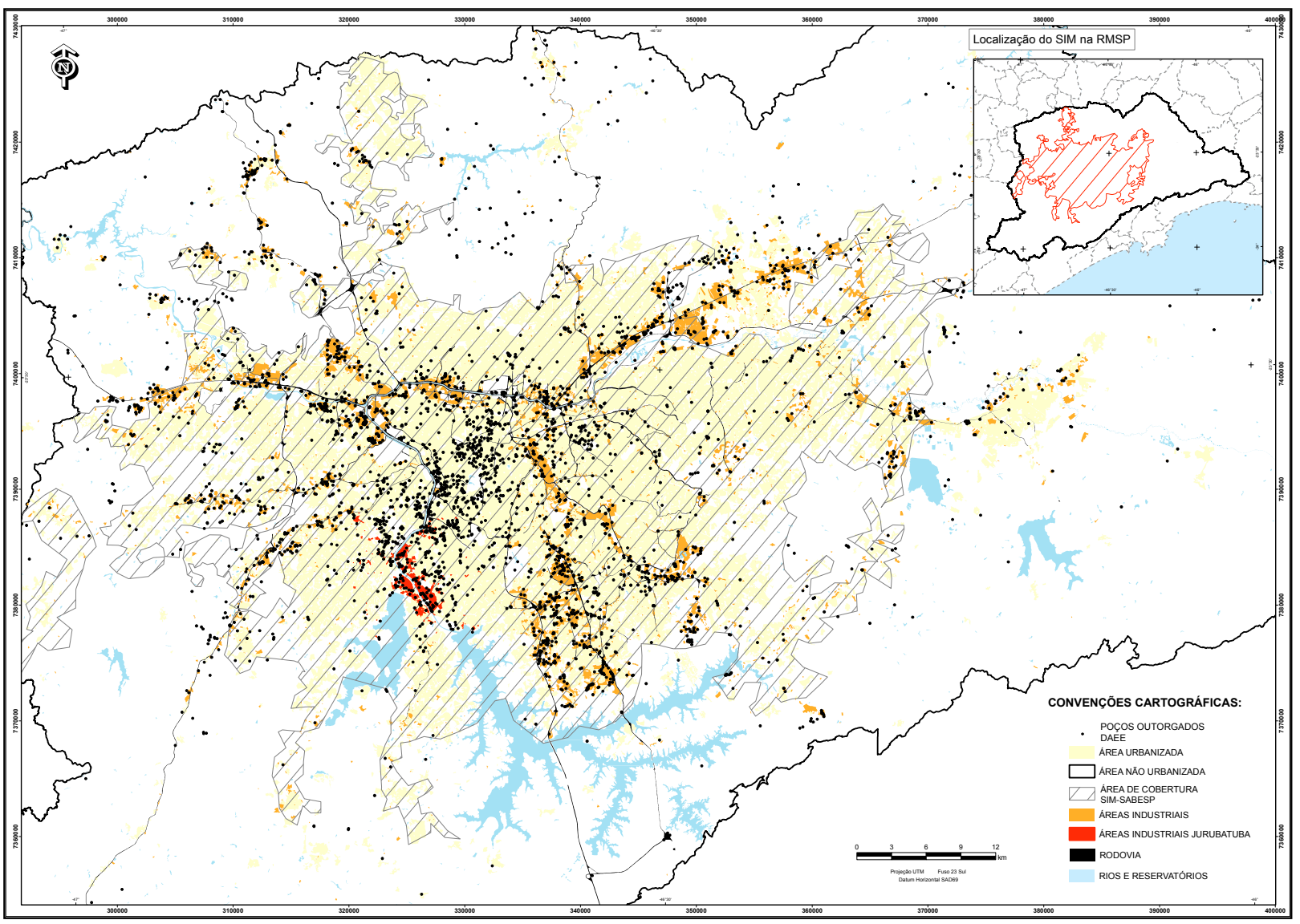

Figura 3 - Localização de poços profundos existentes, áreas urbanas, áreas industriais e área do Sistema Integrado Metropolitano na Bacia Hidrográfica do Alto Tietê e RMSP.

obviamente restringe as ações de governança do recurso hídrico subterrâneo.

A última estimativa do número de poços em operação foi realizada em 2009, para fins de execução do Plano da Bacia Hidrográfia do Alto Tietê (FUSP, 2009). Estimou-se a existência de 12 mil poços profundos à época, retirando uma vazão avaliada em cerca de $10 \mathrm{~m}^{3} / \mathrm{s}$. Do total de poços, apenas 4.931 encontravam-se cadastrados no DAEE ( $F i-$ gura 3). O número total de poços deve ter se elevado nos dias atuais, pois, em função da estiagem dos anos de 2013 e 2014, o ritmo das perfurações, especialmente dos poços irregulares, cresceu de forma dramática, elevando ainda mais a proporção dos poços irregulares sobre os outorgados.
Apesar de existirem muitos poços irregulares, considera-se que os outorgados (Figura 3) já mostram, de forma representativa, as áreas de maior adensamento de poços. Essas áreas coincidem com as regiões de topografia mais suave e mais densamente urbanizadas da RMSP, em que predomina o aquífero sedimentar. Nestas, foram definidas várias zonas aquíferas com sintomas de superexplotação, situação que ocorre quando a taxa de bombeamento supera as vazões de recarga local do aquífero.

Entretanto, a somatória das áreas de maior adensamento de poços e com sintomas de superexplotação é significativamente menor que a área da Bacia do Alto Tietê, que ainda permanece com a maior parte de seus aquíferos pouco utilizada. São 
estas as áreas em que novos poços para abastecimento público podem ser construídos, em especial aquelas em que existem as adutoras e a rede de distribuição do Sistema Integrado Metropolitano (SIM) (Figura 3). Algumas regiões nessa situação coincidem com a periferia da RMSP, na qual não há usuários privados com capacidade econômica para construir poços profundos e há estrutura de adução e reservação de água tratada da Sabesp. Outras regiões de interesse, na área urbana, são as grandes áreas públicas (que incluem os parques), que normalmente não contêm poços. Obviamente, as zonas de superexplotação de aquíferos, coincidentes com as regiões de maior adensamento de poços, devem claramente ser evitadas para esse fim.

- Afirmação 2 - São necessárias centenas de poços para conseguir vazões relativamente pequenas frente à demanda.

A afirmação é verdadeira, considerando os dados existentes de vazões médias dos poços da RMSP, em torno de apenas $8 \mathrm{~m}^{3} / \mathrm{h}$ para ambos os aquíferos sedimentar e cristalino, o que exigiria a operação de milhares de poços para atingir vazões da ordem de alguns $\mathrm{m}^{3} / \mathrm{s}$. De fato, a baixa permeabilidade média dos aquíferos indica que é mais fácil operar os reservatórios superficiais em tempos de abundância de água.

Entretanto, é possível melhorar significativamente a vazão média dos poços caso eles sejam locados com critérios geológicos e construídos de acordo com as normas técnicas. Os dados conhecidos de vazões são provenientes de poços que foram posicionados no único local disponível na área do proprietário do poço e com critérios técnicos de construção limitados pelo orçamento do contratante privado. A grande maioria dos poços certamente não foi locada no melhor lugar possível do ponto de vista hidrogeológico, que, em aquíferos cristalinos, corresponde às fraturas ou zonas de fratura de maior transmissividade.
Um conjunto de poços locados com base em interpretação aerofotogeológica pelo DAEE no aquífero cristalino da Bacia do Alto Tietê resultou em vazões médias de $20 \mathrm{~m}^{3} / \mathrm{h}$ por poço (AGUIAR et al., 1984), muito superior à média de produção dos poços cuja locação é restrita às áreas das propriedades privadas. Atualmente, os dados existentes permitem a realização de tratamento estatístico utilizando ferramentas de Sistema de Informações Geográficas (SIG), como o aplicado em Fernandes et al. (2005), que pode ser usado no sentido de antecipar, de forma regional e local, o conjunto de fatores que determinam uma maior transmissividade para as fraturas. Técnicas modernas, como a utilização de modelos digitais do terreno, que permitem um traçado mais preciso de lineamentos, e imageamentos óptico e acústico de fraturas, bem como medições de velocidades de fluxos dentro do poço, a exemplo do descrito em Fernandes (2008) e aplicado em Wanhfried (2010), que podem mostrar quais são as atitudes das fraturas mais transmissivas, devem ser utilizadas com maior frequência. A aplicação dessas técnicas agregará uma crescente quantidade de dados, que levará à construção de modelos conceituais cada vez mais completos da circulação de água subterrânea nos aquíferos fraturados cristalinos da RMSP, devendo resultar em um sucesso crescente na locação de poços produtivos.

A RMSP viveu um crescimento vegetativo de sua população da ordem de 0,96\% anualmente entre os anos de 2000 e 2010 (IBGE, 2010). Isso significou um acréscimo de quase 1,8 milhão de pessoas na RMSP, resultando numa pressão por elevação da oferta de água para abastecimento da ordem de $6 \mathrm{~m}^{3} / \mathrm{s}$ no período. Isso ocorre num cenário cada vez mais difícil de obter acréscimos de oferta de água superficial, cada vez mais cara e distante. Tomando por base uma vazão média de 20 $\mathrm{m}^{3} / \mathrm{h}$ por poço, seriam necessários 180 poços para obter $1 \mathrm{~m}^{3} / \mathrm{s}$. Essa relação de vazão por número de poços passa a se tornar tolerável à medida que se percebe a existência de áreas para a constru- 
ção de novos poços na RMSP e que o custo para a construção, operação e manutenção de um número significativo de poços se torna possível e competitivo em relação ao custo de obtenção de novas fontes de água superficial.

- Afirmação 3-O controle operacional de miIhares de poços é uma tarefa que implica um esforço grande e que não vale a pena.

Esta afirmação não pode ser considerada inteiramente verdadeira. É fato que seriam necessárias várias centenas de poços para somar vazões que sejam expressivas e condizentes com as demandas da RMSP, da ordem de unidades de $\mathrm{m}^{3} / \mathrm{s}$, mesmo considerando a significativa melhora nas vazões médias individuais de poços locados com critérios geológicos apropriados, como mencionado anteriormente.

Também é fato que o controle operacional de um número tão grande de poços exigiria uma grande atenção por parte do operador do sistema, em especial nas tarefas de aquisição de dados para a tomada de decisões na operação e manutenção dos poços. Cada poço necessita ser monitorado continuamente para vários parâmetros, como vazões, profundidades do nível d'água dinâmico, pressões de recalque, parâmetros elétricos e de consumo de energia das bombas, horas de funcionamento por dia e mês, entre outras informações, os quais precisam ser também integrados com os dados de reservação do sistema de distribuição. 0 cruzamento de todos esses dados permite realizar o gerenciamento ótimo do funcionamento do poço, propiciando obter a melhor relação entre vazões necessárias, explotação segura do

\section{A construção de poços tem prazo relativamente} pequeno, da ordem de dezenas de dias até alguns meses, contra dezenas de meses a alguns anos no caso de captação de corpos de água superficial. ção dos poços, para o que se deve levar em conta a necessidade de um almoxarifado com bombas reservas em estoque, além de estrutura que permita realizar limpezas periódicas nos poços.

O gerenciamento ótimo e integrado de todas essas informações é possível de ser realizado por meio da automação. Nela, um sistema automático de operação e controle por telemetria pode examinar seu próprio funcionamento, realizando medições e correções, com o mínimo de interferência humana.

A instalação do sistema de automação demanda um maior aporte de recursos em curto prazo, mas é um investimento que se amortiza rapidamente, em especial por conta da economia de homem-hora, uma vez que um sistema automatizado possibilita que um colaborador realize a operação a distância e tenha uma visão preditiva de problemas operacionais, permitindo que sejam programadas intervenções preventivas e evitando, assim, as manutenções corretivas, que são sempre mais onerosas e causam a interrupção do fornecimento de água por mais tempo e em momentos, muitas vezes, mais críticos no abastecimento. A automação, portanto, propicia também um maior ganho de eficiência e economia na operação do sistema, resultando em menores desgastes de equipamentos, menores custos de manutenção e menores perdas de produto final.

A construção, operação e manutenção de poços, mesmo que em número de várias centenas, apresentam frequentes vantagens econômicas em relação à construção, operação e manutenção de reservatórios de águas superficiais (REBOUÇAS, 2006). A construção de poços tem prazo relativaaquífero e custos de energia elétrica, além da identificação de problemas que exigem a manutenção do poço. $O$ controle operacional também inclui as tarefas de manuten- mente pequeno, da ordem de dezenas de dias até alguns meses, contra dezenas de meses a alguns anos no caso de captação de corpos de água su- 
perficiais em geral demandam maiores custos e esforço humano que aqueles exigidos em poços que, quando apresentam alguma necessidade de adequação da qualidade natural da água captada, esta se faz por meio de estações compactas e automáticas de tratamento de água, que representam baixos custos relativos de implantação e de operação. Desse modo, os custos de um sistema de abastecimento por água subterrânea, extraindo a mão de obra, praticamente se resumem à manutenção de bombas elétricas submersíveis e limpeza periódica dos poços. Além disso, os mananciais subterrâneos não sofrem perdas de água por processos de evaporação ou assoreamento, tal como ocorre nos reservatórios superficiais.

Os custos relacionados com a explotação de água subterrânea por poços se tornam proibitivos em situações em que os custos de energia elétrica são mais elevados que os do tratamento químico da água superficial. Entretanto, gastos elevados com energia elétrica ocorrem notadamente nos casos em que a água subterrânea se situa em grandes profundidades no poço, circunstância que normalmente está associada com quedas de vazões e, consequentemente, com sintomas de superexplotação do aquífero. Nesse caso, a explotação do aquífero deve ser de fato evitada.

No entanto, a explotação de água subterrânea e o seu controle operacional se tornam ainda mais vantajosos na condição em que a instalação de um campo de poços seja tecnicamente viável. Dessa forma, os poços são locados em posições estratégicas em uma determinada área - geralmente fora da zona urbana -, visando a otimizar ao máximo as vazões extraídas do aquífero. Entre as vantagens da instalação de campo de poços, estão as possibilidades de (1) conhecer mais profundamente as características de reservação, recarga e fluxo de água dos reservatórios aquíferos explotados, permitindo que sua explotação seja mais eficiente; (2) otimizar os custos de adução e automação do conjunto de poços, uma vez que 
estes se encontram mais próximos entre si; e (3) estabelecer ferramentas de governança da água mais eficazes, visando à proteção do aquífero contra atividades poluidoras em superfície, por meio de uma política de uso e ocupação do solo no local.

- Afirmação 4 - A água subterrânea na RMSP tem baixa qualidade por causa da poluição.

O gerenciamento de áreas contaminadas, necessário devido à poluição de solo e aquíferos, é de grande interesse ambiental, porém a baixa qualidade da água subterrânea restringe-se a determinadas áreas. Uma evidência disso é que os milhares de poços tubulares profundos legais existentes, que se espalham especialmente em grande parte da área urbanizada da RMSP, receberam outorga de uso, pois as análises químicas requeridas demonstraram que a água era potável. Em geral, a água dos reservatórios subterrâneos, em especial aquela captada das porções mais profundas do aquífero, é mais bem protegida da poluição do que a água dos reservatórios superficiais, por conta das baixas velocidades de infiltração e dos processos biofisicogeoquímicos que se desenvolvem no aquífero e que proporcionam atenuação das concentrações dos principais agentes poluentes.

Os casos mais comuns de não potabilidade de águas de poços tubulares profundos na RMSP devem-se a ocorrências naturais de ferro dissolvido. Secundariamente, o manganês também pode ocorrer em concentrações acima dos limites. As concentrações desses elementos geralmente não representam perigos do ponto de vista toxicológico, mas apenas uma restrição organoléptica. A água, nessas condições, pode ter o ferro e o manganês removidos mediante tratamentos simples e de baixo custo. Casos de ocorrência natural acima da potabilidade do íon fluoreto são mais raros e, quando ocorrem, são em área reduzida, como na região do bairro da Barra Funda.
É provável que a sociedade possua uma percepção de que toda a água subterrânea na RMSP é de baixa qualidade por causa da existência de muitas áreas contaminadas, cujas fontes de poluição são associadas principalmente com vazamentos de esgotos, de tanques de combustíveis em postos de serviços e de substâncias químicas perigosas em áreas industriais. Todas essas fontes de poluição, entretanto, se relacionam com as áreas mais densamente urbanizadas e que não representam a totalidade da área da RMSP, restando pelo menos $50 \%$ de áreas rurais e de florestas (Figura 3).

Mesmo nas áreas fortemente urbanizadas, não se pode dizer que toda a água subterrânea é de baixa qualidade. Os poluentes que se relacionam com vazamentos de tubulações de esgoto (carga orgânica) e de tanques de combustíveis em postos de serviços (hidrocarbonetos) em geral criam maiores impactos no aquífero freático raso. Observa-se, entretanto, que esses poluentes sofrem processos de biodegradação aeróbica e/ ou anaeróbica relativamente rápidos até poucas dezenas de metros de profundidade. Como consequência, a água subterrânea de aquíferos com captações mais profundas (maiores que $100 \mathrm{~m}$ ) é de melhor qualidade e, em geral, apta para pronto consumo humano.

Os poluentes de aquíferos associados com as atividades industriais podem ser bastante numerosos, muito deles móveis e relativamente persistentes, mesmo em aquíferos mais profundos. Talvez o caso mais emblemático de contaminação de origem industrial em aquíferos profundos seja o que ocorre na região do Canal do Jurubatuba, zona sul de São Paulo. Nesse local, a existência de fontes múltiplas de contaminação de compostos etenoclorados, utilizados como solventes e provenientes de várias indústrias, ocasionou a contaminação do aquífero em profundidades que alcançam $300 \mathrm{~m}$, comprometendo o abastecimento de uma grande quantidade de usuários e causando prejuízos da ordem de vários milhões 


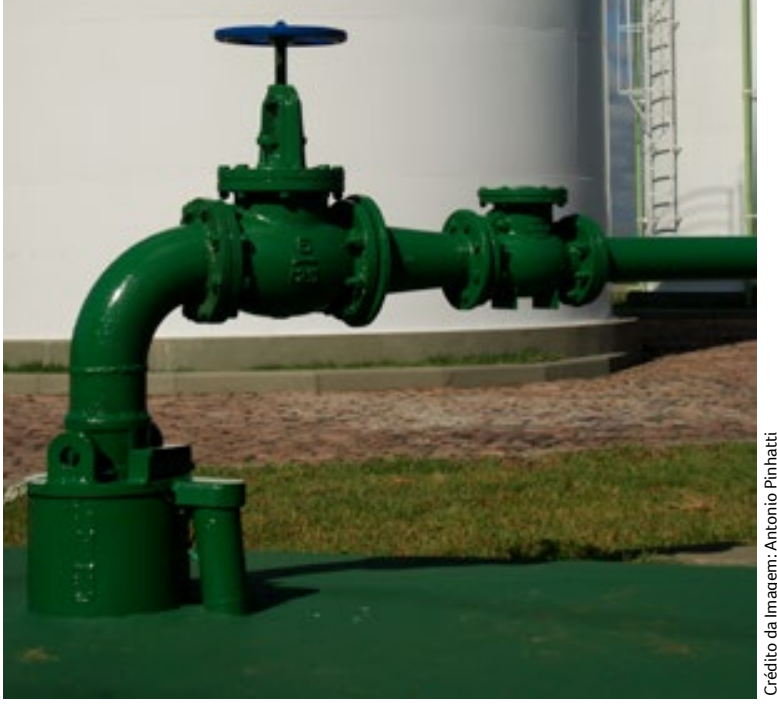

de reais por ano. Não se descarta haver outras áreas industriais com problemas semelhantes ao do Jurubatuba na RMSP, mas não é correto afirmar que toda a água subterrânea na região urbana da RMSP tem qualidade comprometida por conta de atividades industriais, visto que é evidente, pela Figura 3, que as zonas industriais (em laranja) ocupam uma área relativamente pequena em relação à área total da RMSP. A Figura 3 apresenta, também, a informação de que grande parte dos poços profundos outorgados está localizada exatamente nas áreas industriais, apresentando, por conseguinte, água em condições de potabilidade.

\section{CONSIDERAÇÕES FINAIS}

A resposta à pergunta formulada no título deste trabalho é: "Sim, é possível utilizar água subterrânea em larga escala para complementar o sistema de abastecimento público na RMSP”. Em síntese, as razões que levam a essa afirmação são:

- a quantidade de água subterrânea passível de explotação é da ordem de $30 \mathrm{~m}^{3} / \mathrm{s}$ na área da RMSP, correspondente a $50 \%$ do volume infiltrado nos solos a partir das chuvas;

- a maior parte dos milhares de poços existentes concentra-se nas porções mais urbanizadas e industrializadas da RMSP. Estima-se que esses poços possam extrair $10 \mathrm{~m}^{3} / \mathrm{s}$, restando pelo menos uma vazão de $20 \mathrm{~m}^{3} / \mathrm{s}$ para ser explotada em áreas de baixa densidade de poços;

- embora as vazões médias individuais dos poços existentes sejam baixas, considera-se ser possível elevá-las por meio da locação de poços que utilizem critérios geológicos e hidrogeológicos, passíveis de ser identificados e analisados devido às técnicas atualmente disponíveis;

- considera-se possível alcançar vazões da ordem de $1 \mathrm{~m}^{3} / \mathrm{s}$ com a locação adequada de 180 poços, contribuindo de forma expressiva para o abastecimento público, tanto em situações normais quanto nas de estresse hídrico. A operação e manutenção desse número de poços são plenamente possíveis mediante a implantação de sistemas automatizados e de telemetria, cuja utilização em larga escala e em longo prazo apresenta vantagens econômicas;

- a perfuração e instalação dos 180 poços para a produção de $1 \mathrm{~m}^{3} / \mathrm{s}$ apresentam, em valores atuais, um custo de $\mathrm{R} \$ 38$ milhões, o que resulta num custo adicional de $R \$ 0,05 / \mathrm{m}^{3} \mathrm{em} 30$ anos de amortização, valores bastante competitivos em relação aos custos de construção de reservatórios superficiais;

- as águas subterrâneas bem captadas apresentam, em geral, boa qualidade, dispensando o tratamento químico, obrigatoriamente utilizado para tratamento de águas superficiais;

- as águas subterrâneas não geram resíduos sólidos para ser posteriormente gerenciados, o que representa um interessante fator de competitividade;

- aquíferos contaminados existem e necessitam ser corretamente gerenciados. Entretanto, um bom programa de locação de novos poços pode fornecer águas subterrâneas de boa qualidade, desde que se evitem as áreas industriais e as áreas de grande adensamento de poços e 
se obedeçam às normas técnicas de construção de poços.

A adição de um grande número de poços tubulares profundos no SIM certamente exigiria uma mudança de cultura por parte dos operadores do sistema, muito mais habituados com a operação de reservatórios de águas superficiais. Outros conceitos precisariam ser integrados àqueles já consolidados na comunidade técnica, como hidráulica de aquíferos e operação e manutenção de poços, o que pode ser suprido rapidamente por meio de treinamentos. A Sabesp, inclusive, já faz a operação de mais de mil poços para abastecimento público, espalhados por vários municípios do interior do estado de São Paulo, e conta com técnicos em hidrogeologia muito experientes e capazes.

A entrada em operação de um bom número de poços voltados para abastecimento público certamente tornaria mais complexa a gestão dos recursos hídricos na RMSP, exigindo maiores responsabilidades dos gestores. Esta seria de fato uma grande ocasião para o planejamento e implantação de um verdadeiro plano de gestão integrada de recursos hídricos superficiais e subterrâneos, baseado em um autêntico mecanismo de outorga e fiscalização dos direitos de uso dessas águas, bem como na aplicação de medidas visando à

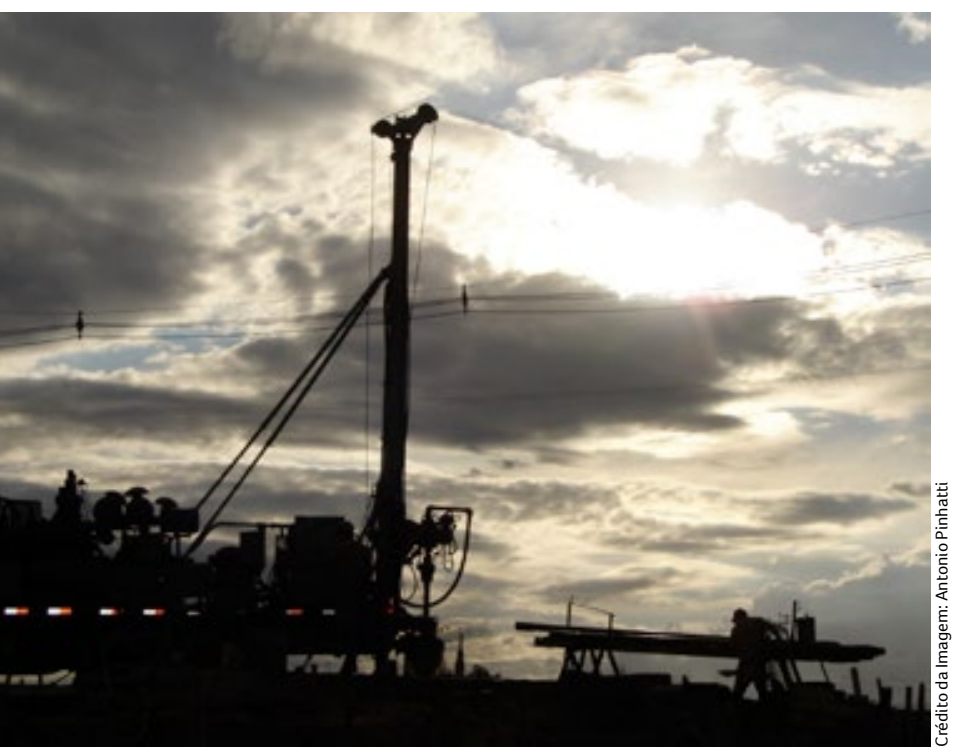

conservação dos recursos hídricos superficiais e subterrâneos, tal como já previsto no arcabouço de leis vigentes.

No caso das águas subterrâneas, tem havido faIhas na realização dessas tarefas, pois a grande maioria dos poços profundos em funcionamento é clandestina, provavelmente porque a outorga é considerada pelo usuário de água subterrânea uma exigência cartorial, cara e desnecessária. 0 usuário não vê, portanto, quais seriam as vantagens na realização da outorga de uso ao gestor. Também é fato que os órgãos gestores são instituições desaparelhadas e com quantidade bastante limitada de técnicos nos seus quadros. Nessas condições, com tantos poços clandestinos e sem um efetivo disciplinamento do uso privado da água, é mais difícil de realizar a avaliação, a conservação e o planejamento racional, bem como a fomentação do uso adequado dos recursos hídricos subterrâneos, situação desejada para a utilização da água subterrânea como alternativa para o abastecimento público.

Como sugestões, avalia-se que o estado necessita executar uma série de ações, tais como:

- facilitar e desonerar os processos de licença de perfuração e de outorga de uso da água, inclusive implementando o processo eletrônico via internet;

- estabelecer programas efetivos de comunicação social e educação ambiental, incluindo os perfuradores, os usuários e a sociedade, visando a demonstrar a importância desses atores no processo de gestão dos recursos hídricos, mas, sobretudo, motivar o usuário a se regularizar e também ser um agente fiscalizador e multiplicador do processo de gestão;

- diminuir as exigências documentais do processo de outorga, transferindo ao usuário e ao profissional registrado no Conselho Regional de Engenharia e Agronomia (CREA) a respon- 
sabilidade pelo teor e veracidade das informações prestadas no processo;

- reaparelhar os órgãos fiscalizadores, em especial o DAEE, fortalecendo os escritórios regionais, ampliando o corpo técnico capacitado e modernizando as ferramentas necessárias à adequada gestão dos recursos hídricos subterrâneos;

- revisar a legislação, tornando claras as penalidades pelo não cumprimento da outorga, com responsabilidades objetivas a todos os atores do processo, principalmente, usuários, profissionais técnicos e empresas perfuradoras;

- depois de um amplo programa de regularização, fortalecer e modernizar o processo de fiscalização e controle pelo uso dos recursos hídricos subterrâneos, aumentando o alcance e a efetividade da aplicação da lei e da punição aos usuários clandestinos;

- melhorar a comunicação e interação entre as instituições responsáveis, aplicando efetivamente as políticas, a estrutura e os instrumentos do Sistema de Gerenciamento dos Recursos Hídricos em vigor.

Os desafios que as águas têm colocado para a nossa sociedade não são fáceis e exigem que os gestores se reorganizem e reinventem processos, busquem novas alternativas economicamente viáveis de elevação da oferta, tomem decisões buscando ótimas condições de consumo e acelerem os processos de tratamento e reúso das águas. Nesse cenário, a água subterrânea, sem dúvida, é um recurso generoso e está disponível para ajudar a amenizar os desconfortos dos dias de escassez.

\section{REFERÊNCIAS}

AGUIAR, A.; ANDRADE, E.P.; SILVA, R.B.; HIRATA, R. 10 anos de experiências acumuladas na exploração de recurso hidrico subterrâneo. In: CONGRESSO BRASILEIRO DE ÁGUAS SUBTERRÂNEAS, 1984, Fortaleza, Ceará. Anais do 30 Congresso Brasileiro de Águas Subterrâneas. FORTALEZA, CEARA: ABAS, 1984, p. 1-13.
CAMPOS, J.E.; ALBUQUERQQUE FILHO, J.L. Aquíferos São Paulo. In: Rocha G., Fernandes A.J., Mancuso M. (ed.) Mapa de Aguas Subterrâneas do Estado de São Paulo, Nota explicativa, DAEE/IG/CPRM/ IPT, 2005, p. 52-56.

CONICELLI, B. P. Gestão das Águas Subterrâneas na Bacia Hidrográfica do Alto Tietê (SP). Tese (Doutorado) - Instituto de Geociências - Universidade de São Paulo, São Paulo, 2014, 163 p.

DIAS, J.P.; BABINSKI, M.; HIRATA, R.; MANCINI, L.; ROSÁRIO, M.; AZEVEDO, A.E. Caracterização isotópica da precipitação da cidade de São Paulo (Brasil) e sua relação com as águas subterrâneas. Anais do VIII Congresso de Geoquímica dos Países de Lingua Portuguesa. Aveiro, Universidade de Aveiro; Sociedade Brasileira de Geoquímica; Sociedade Geológica de Portugal, 2005. p. 433-436.

FERNANDES, A.J.; PERROTA, M.; SALVADOR, E.; AZEVEDO, S.; GIMENEZ FILHO, A. STEFANI, F.; PAULON, N. Aquíferos Fraturados. In: G. Rocha, A.J. Fernandes, M. Mancuso (ed.) Mapa de Águas Subterrâneas do Estado de São Paulo. Nota explicativa. DAEE/IG/ CPRM/IPT, 2005, p. 66-84.

FERNANDES, A.J. Aquíferos Fraturados: uma revisão dos condicionantes geológicos e dos métodos de investigação. In: Revista do Instituto Geológico, São Paulo, 29 (1/2), 2008, p. 49-72.

FUSP Fundação de Apoio à Universidade de São Paulo. Plano da Bacia Hidrográfica do Alto Tietê - Relatório Final. 2009. 4 volumes. Disponível em http://www.fabhat.org.br/site/images/docs/ volume_1_pat_dez09.pdf. Acessado em 31/03/2015.

HIRATA, R.; BERTOLO, R.; CONICELLI, B. ; MALDANER, C. Hidrogeologia da Bacia Hidrográfica do Alto Tietê. In: Negro, A.; Namba M.; Sanches, V.; Dyminski A.; Kormann, A. (Eds.). Twin Cities: Solos das Regiões Metropolitanas de São Paulo e Curitiba. 1ed. São Paulo: D'Livros, 2012, v. 1, p. 67-82.

HIRATA, R.; FERRARI, L.; FERREIRA, L.; PEDE, M. La explotación de las aguas subterráneas en la cuenca hidrográfica del Alto Tietê: cronica de una crisis anunciada. Boletín Geológico y Minero, Madrid, v. 113, n.3, 2002, p. 273-282.

HIRATA, R.; FERREIRA, L. Os aquíferos da bacia hidrográfica do Alto Tietê: disponibilidade hídrica e vulnerabilidade à poluição. Revista Brasileira de Geociências, São Paulo, v. 31, n.1, 2001, p. 43-50.

IBGE (Instituto Brasileiro de Geografia e Estatística). Censo 2010. Disponível em http://www.censo2010.ibge.gov.br/ , Acessado em 13/02/2015.

REBOUÇAS, A.C. Águas Subterrâneas. In Rebouças, A.C.; Braga, B., Tundisi, J.G. (org.). Águas doces no Brasil. Escrituras Editora, São Paulo, $3^{\mathrm{a}}$ edição, 2006, p. 111-114.

WAHNFRIED, I. 2010. Modelo conceitual de fluxo do Aquitarde Serra Geral e do Aquífero Guarani na Região de Ribeirão Preto / SP. Tese de Doutorado. Instituto de Geociências, São Paulo, 122 p. 